\title{
Introdução por um grilo falante
}

Candido Alberto Gomes

Solicitado honrosamente a introduzir o número 101 de Ensaio: Avaliação e Políticas Públicas em Educação, concebo a minha tarefa como a do Grilo Falante, alguém que vê a partir de outra perspectiva, de conjunto, a estabelecer ligações, episódios de bastidores e a abrir portas para a curiosidade científica. Não, claro, um detector do certo/errado, verdadeiro/falso, completo/incompleto, isto porque colegas já o fizeram, a incentivar os artistas das pedras preciosas a lapidá-las ainda mais. Assim fiz - e peço licença para escrever na primeira pessoa do singular - muitas vezes como avaliador, ciente e consciente dos limites tanto do avaliador quanto dos avaliandos. Fernando Pessoa expressou poeticamente estas percepções que temos na epistemologia. Como cientistas, nos propomos a ver até ao fundo, a experimentar diversas perspectivas, o que o artista descreve em Isto (PESSOA, 1996, p. 43):

Tudo o que sonho ou passo,

O que me falha ou finda,

É como que um terraço

Sobre outra coisa ainda.

Essa coisa é que é linda.

De fato, essa coisa é que é linda e, nos nossos cativos limites, verdadeira ao menos por certo tempo, como a sombra fugidia de uma ave sobre um rio de águas sempre em movimento. Estabelecido o significativo marco do número 100 deste Periódico, fruto da semeadura paciente e contínua, não me cabe juntar as peças do mosaico aqui apresentadas. Bem tentei, mas descobri que, dentro de cada um de nós, está a figura na qual encaixaremos a peça em nosso próprio mosaico. Por isso mesmo, Ensaio continua a singrar no rumo da pluralidade temática, teórica e metodológica, em coerência com os princípios e mandamentos da Organização das Nações Unidas (ONU), da Organização das Nações Unidas para a Educação, a Ciência e a Cultura (Unesco) e da nossa própria Constituição. Assim, procuro, primeiro, fazer uma apresentação comentada, para depois apresentar comentários que espero oportunos.

\footnotetext{
a Editor-Adjunto. Prof. Catedrático da Universidade Portucalense Infante D. Henrique. Porto, Portugal.
} 
Abre-se este fascículo com o artigo de Ferreira e Ramos sobre um dos nós górdios do Brasil: o ensino médio. "O Projeto de Medida Provisória n ${ }^{\circ} 746$ : entre o discurso e o percurso de um novo ensino médio" procede às análises documental e de conteúdo da Medida Provisória correspondente, depois de alterações, convertida em Lei. É base relevante para pesquisas ulteriores. Vale citar a memória pessoal quanto ao pano de fundo: numerosas audiências públicas, mais de 50 Projetos de Lei alterando o ensino médio e, sobretudo, acrescentando disciplinas ao enciclopédico currículo. Em grande parte, busca de mudanças lineares, por aposição, e não estruturais. E falta de decisão, enquanto a matrícula continua a recuar. Os autores com correção assinalaram ser uma reforma sem recursos, que rima com discursos. Há décadas, conforme as áreas de governo, o pêndulo se desloca entre duas posições ideológicas, assim figuradas nos extremos: ou a educação brasileira precisa sempre de dinheiro, sem se ligar muito para o aproveitamento dele, apesar da transição demográfica, ou a educação tem dinheiro demais que não sabe aplicar. Necessitaria, neste caso, de vontade política e melhor aproveitamento de recursos. É parcialmente verdade, mas a miséria das escolas está aí. Recomenda-se a leitura de Saramago (1995), "Ensaio sobre a cegueira", pois toda ideologia é deficiente visual, cômoda, além de internamente bem concatenada.

No âmbito ibero-americano, muito bem-vindo, sucede "A educação de adultos em Portugal: novas arquiteturas educativas à luz do modelo neo-institucional", de Silva. Nó górdio lá como cá, é vã a esperança de uma espada para cortá-lo ou do regresso de D. Sebastião, glorioso, de Alcácer-Quibir. O trabalho fundamenta-se na teoria da hipocrisia organizacional de Brunsson, aliás, no Brasil precedida pelo enfoque histórico-filosófico de Anísio e pelo organizacional de Beno Sander (LIRA, 2010). O foco está na participação do avaliador externo, sociologicamente relevante, nos processos de reconhecimento, validação e certificação de competências. Dependendo do país e da conjuntura, este funil é mais ou menos apertado, fugindo do princípio aristotélico de que a verdade está no meio.

Hurra Herrera e Cancino Cancino analisam a experiência de assessoramento da Universidad de Talca e do Ministério da Educação a equipes diretivas da região de Maule, Chile. Destacam que, na literatura internacional, tais equipes são a segunda variável intraescolar com impacto sobre o desempenho dos estudantes. Seu objetivo foi o fortalecimento de lideranças educativas nos estabelecimentos, com a realização de oficinas. Com efeito, diretores e professores precisam ser líderes. E, para Weber (1999), no seu enfoque das formas de dominação, os carismáticos são eminentemente líderes, o que liga, entre outros, com a obra de Dubet (2002) sobre o estilhaçamento da escola como instituição da modernidade em crise. $\mathrm{O}$ caso dos colegas chilenos é uma advertência para todos, vizinhos e não vizinhos: a experiência foi limitada, ela e a avaliação se defrontaram com obstáculos. Um 
procedimento frequente, nos ciclos eleitorais, é apagar o que ficou para trás, como se governos fossem mais que o Estado, para seguir noutra direção. A avaliação e o projeto deixam lacunas, os leitores au pied de la lettre, na sua busca por impactos palpáveis, com frequência no mundo ideológico da quantofrenia ou doença dos números (DE GAULEJAC, 2007), descartam a experiência, em vez de levá-la à frente, superando os seus limites. Trata-se de um círculo vicioso a superarmos.

Em prosseguimento, Ferreira, Berbenbrok-Rosito e Almeida apresentam os importantes resultados de uma pesquisa em: "Teaching and researching quality indicators: a partnership with middle school students". Seu objetivo foi verificar como alunos do $9^{\circ}$ ano do ensino fundamental entendem a qualidade da educação. Encontraram quatro grupos de significados: 1) competência profissional, inclusive indo além da cópia; 2) escola como ambiente psicossocial ou que sua fisionomia não seja de precariedade; 3) confiança na parceria alunos-educadores; 4) respeito: considerar e incluir a todos, com participação.

Voltamos, então, a Portugal e a "Autoavaliação das escolas: o caso do grupo disciplinar de Biologia/Geologia", por Carvalho e Correia. Foi realizado estudo de caso numa escola pública do Norte, onde, apesar da preocupação com a qualidade, as ações surgiam predominantemente como resposta à avaliação externa, não à autoavaliação. Esta última era um procedimento imposto, em que, conforme os participantes, variavam o tipo e o grau de participação. Os torniquetes da avaliação externa alimentam o quantitativismo e hoje rememoram o que meus professores de avaliação já avisavam no início dos anos 1980 (por exemplo, POPHAM, 2000). Poderíamos achar um paralelo entre o comportamento da escola e o de uma parte dos alunos, que focaliza as provas e as notas em detrimento de tudo o mais? Têm eles apenas test-wiseness ou são capazes de aprender a conhecer, a fazer, a conviver e a ser?

Macena, Justino e Capellini dão continuidade com a análise do Segundo Plano Nacional de Educação (2014-2020) e dos desafios para a Educação Especial na perspectiva de uma cultura inclusiva. Rios de tinta poderiam fluir, o que a extensão de um artigo não permite. $\mathrm{O}$ trabalho acentua a importância da criação de novas culturas inclusivas, o que talvez, em nossa opinião, falte ao Brasil em todas as dimensões: social, étnica, econômica e nas demais faces desta sociedade poliédrica. Um dado que merece ser frisado aqui é a relativamente alta proporção de escolas municipais que não utilizam salas multifuncionais. Por quê? Conforme o poeta, é um terraço sobre alguma coisa ainda.

Adiante, Pereira apresenta pesquisa na região central do Rio Grande do Sul, "O sistema municipal de ensino em análises: avanços e desafios". Na esteira 
histórica da descentralização, a constitucionalização dos sistemas municipais de ensino, lembra-se vividamente este autor, surgiu na Comissão de Educação da Constituinte, quando se debatia o Relatório e Parecer a serem encaminhados à Comissão de Sistematização. Numa reunião, o Deputado Constituinte Octavio Elísio propôs e foi aceito nomear também tais sistemas, apesar das dúvidas sobre a capacidade daqueles entes federativos e a influência nele de certos grupos políticos, não propriamente. A pesquisa demonstra o grau de formalidade da adesão legal a este conceito, rememorando Brunsson, Teixeira e Sander. Aduzamos que o pêndulo, já inclinado na direção da descentralização das receitas, ainda no governo militar, levou também à descentralização do Fundef. A literatura internacional mostra resultados dúbios em relação ao binômio centralização/ descentralização. Mons (2004.) esmiuçou as pesquisas e verificou que certas dimensões da centralização têm impactos positivos sobre os alunos e as escolas, ao passo que certas dimensões da descentralização apresentam também impactos positivos. Em outros termos, é mais prudente buscar abordagens desagregadoras.

Em seguida, passamos à educação delegada à família na Colômbia. Sem dúvida, o país tem áreas remotas, com diversas paisagens socioculturais, onde o deslocamento é difícil. Mesmo de um vale para uma montanha e vice-versa o transporte pode ser curto na extensão, embora incompativelmente longo no tempo. O trabalho questiona a escola sob vários ângulos. Efetivamente, ela se dessacralizou na crise da modernidade. $\mathrm{O}$ que era aparentemente um lugar de cuidado e até refúgio se tornou cenário de violências da/na/contra a escola. Há decênios atrás, um criminoso não ousava furtar uma imagem de uma das nossas igrejas históricas. Todavia, os mercados estimulam a furtar não só os templos históricos, mas também os que não são. É bem verdade que a dessacralização mais se refere aos alunos e à comunidade, quando esta existe sociologicamente, pois a violência da escola e de professores é antiga. Que o diga Raul Pompeia (s.d.) na sua autonarrativa de $O$ Ateneu.

É tempo de lembrar também da decisão recente do Supremo Tribunal Federal do Brasil sobre o assunto, reiterando o papel da escolarização. Como não somos ingênuos, precisamos divisar o que vem no fluxo de ideias bem-intencionadas. Há um mercado de educação familiar, com empresas grandes e pequenas para o apoio mais ou menos padronizado, como há mercado para explicadores, sejam pessoas físicas ou jurídicas. Cui bono?

Soares e Farias prosseguem com "Vem educar com a gente: o incentivo do governo e escolas à coprodução da educação por familiares de alunos". O artigo aborda uma iniciativa do Distrito Federal nesse sentido. Os resultados apontam 
para apoio e sanções aos pais, como o Programa Bolsa Família. As escolas geram aproximação por meio de eventos e âmbitos de participação, como conselhos escolares e reuniões com pais. Estas são questões presentes no âmbito internacional, que demandam análises como estas e seus desdobramentos. Haverá um hiato sociocultural entre escolas, burocracias públicas, e pais (ou famílias fragmentadas e recompostas)? As pontes são eficazes? Existem muitos pais socialmente desfavorecidos (a mobilidade educacional intergeracional tem sido uma característica do Brasil), com dificuldades em entenderem o próprio valor da escolarização e sem possibilidades de ajudar os filhos em suas tarefas escolares. Resultados de uma pesquisa, ainda inédita, informam que uma parte dos alunos não consegue apresentar os trabalhos para casa, por falta de lugar e tempo adequados, de meios para pesquisa e de auxílio, a não ser por irmãos mais velhos. Ao menos num estudo de caso, o estabelecimento resolveu substituir tais trabalhos por outras atividades. A decisão não é estapafúrdia: na presidência de François Hollande, discutiu-se seriamente se os deveres deveriam ser para todos ou abolidos. Afinal, na bandeira tricolor, a liberdade é azul, a igualdade é branca e a fraternidade é vermelha.

Algumas reflexões finais levam em conta novos horizontes para a educação. Primeiro, temos neste número ampla diversidade metodológica: pesquisas quantitativas e qualitativas, análises de bancos de dados, estudos de caso, entrevistas abertas ou semiabertas, pesquisas documentais, numa diversidade criadora. É notório que grande parte (maioria?) das pesquisas educacionais brasileiras, oriundas principalmente de dissertações e teses, têm menor escopo e dependem das possibilidades de tempo e outras condições de professores e pós-graduandos, o que não minimiza o seu valor. Contudo, há certo consenso de que faltam pesquisas mais amplas, inclusive, que possam dar prosseguimento a pesquisas exploratórias inspiradoras. Por outro lado, é impressão pessoal que as investigações científicas têm se afunilado, buscando com frequência a análise de documentos, menores amostras e trabalho com grandes bancos de dados. Tudo isto é fruto de a educação sempre poder esperar. A desculpa mais constante é a limitação de recursos financeiros, nos ciclos de vacas magras, e também nos de vacas relativamente gordas. É certo que a quantidade de recursos é indispensável, mas não suficiente para reformular agendas, buscar novas perspectivas e escapar ao mais do mesmo. Já se acusou a pesquisa dos Programas de Pós-Graduação de não contribuir para mudar a educação no Brasil, supondo relação linear e reducionista. Uma das interpretações era que tinha quantidade, mas não talvez foco e qualidade. Uma das respostas - muito justas - foi de que a pesquisa existe, mas os decisores não querem saber dela. Um pingue-pongue similar ao do cenário internacional. Urge, pois, construir pontes e demolir muros. 
No desdobramento deste "Admirável Mundo Novo", em que as redes informacionais e os grandes conjuntos de dados são controlados por poucas entidades transnacionais, precisamos estar conscientes das novas tendências impressas à arquitetura da pesquisa. Precisamos indagar e refletir sobre a planetarização, não somente sobre a existência humana, mas da humanidade inteira, finita no espaço e no tempo, em contraste com a política, de curto prazo e em escala nacional. Vivemos no tempo de poderosas redes informáticas, que desnudaram a nossa intimidade como cavalos de Troia; situamo-nos no horizonte do pós-humano e da inteligência artificial, que nos reservam grandes incógnitas. Viramos metáforas: somos uma sociedade ou uma rede de máquinas? Somos seres humanos ou cyborgs, a cruzar as fronteiras entre o vivo e o artificial? Afinal, seremos organismos ou máquinas, passando do homem "consertado" ao homem "aumentado"? Ou híbridos? Com tamanha concentração de poder em pequenos grupos transnacionais, o que será da democracia? (CHAZAL, 2018).

Estes fenômenos sociais totais (MAUSS, 2002) repercutem sobre as mais variadas dimensões, inclusive uma revolução epistemológica silenciosa: com as massas de dados acumulados e organizados, afora os processos robotizados, se verifica a tendência da ciência in silico por meio de quase experimentos, em vez de in vivo ou in vitro, com o abalo do status da hipótese e do experimento (GANASCIA, 2018). Analisam-se grandes massas de dados, como intermediárias da realidade, que nós mesmos pagamos. Segundo estimativa, um internauta proporciona anualmente, com os seus dados, um bilhão de dólares aos gigantes da tecnologia (ALEXANDRE, 2017). Estaríamos no rumo da ciência robotizada, por meio da inteligência artificial e seu cortejo?

Há certo consenso de que não vivemos do fatalismo ou do determinismo. Expressando as contradições, se há um lado direito, há um lado avesso. E há esperança, não ingênua, mas de quem pensa, sente e age. Este é o paradoxo retratado pelo poeta, que vale para a ciência (PESSOA, 2006, p. 121):

Quem está no sol e fecha os olhos, Começa a não saber o que é o sol, E a pensar muitas coisas cheias de calor.

Mas abre os olhos e vê o sol, E já não pode pensar em nada, Porque a luz do sol vale mais que os pensamentos

De todos os filósofos e de todos os poetas. 


\section{Referências}

ALEXANDRE, L. La guerre des intelligences : intelligence artificielle versus intelligence humaine. Paris : JC Lattès, 2017.

CHAZAL, G. La révolution numérique et l'horizon du posthumain. In :

ZARKA, Y. C. ; GODIN, C.; TAUSSIG, S. (Orgs.). Les révolutions du XXIe.

Siècle. Paris: PUF, 2018. p. 125-34.

DE GAULEJAC, V. Gestão como doença social: ideologia, poder gerencialista e fragmentação social. Aparecida : Ideias e Letras, 2007.

DUBET, F. Le déclin de l'iinstitution. Paris : Du Seuil, 2002.

GANASCIA, J.-G. Sciences in silico. In : ZARKA, Y. C.; GODIN, C.; TAUSSIG, S. (Orgs.). Les révolutions du XXIe. Siècle. Paris : PUF, 2018. p. 151-62.

LIRA, A. Resenha: The consequences of decision making. Nils Brunsson Oxford: Oxford University Press, 2007. Cadernos de Pesquisa, v. 40, n. 139, p. 305-19, jan./abr. 2010. https://doi.org/10.1590/S0100-15742010000100015

MAUSS, M. Manuel d'étnographie. Paris : Payot, 2002.

MONS, N. Réformes décentralisatrices, efficacité et equité des systèmes éducatifs : éclairage international. In: GURGAND, M. et al. (eds.). Quel est l'impact des politiqes éducatives? Les apports de la recherche. [S. L..] : Commission du Débat National sur l'Avenir de l'École, 2004.

PESSOA, F. Poesias. Porto Alegre: L \& PM, 1996. , Poesia de Fernando Pessoa. Queluz de Baixo: Presença, 2006.

POMPEIA, R. O Ateneu. Rio: Fundação Biblioteca Nacional, s. d.

POPHAM, J. J. Testing! Testing! What every parent should know about school tests. Needham Heights, MA: Allyn \& Bacon, 2000.

SARAMAGO, J. Ensaio sobre a cegueira. Rio de Janeiro: Companhia das Letras, 1995.

WEBER, M. Economia e sociedade. 4. Ed. Brasília: Ed. UnB; 1999. Vol. 1.

\section{(c)) BY-NC}

